\title{
Anodal stimulation as a cause of pacemaker-induced ventricular fibrillation
}

Thomas A. Preston, M.D.

Ann Arbor, Mich.

$\mathrm{T}$ The possibility of pacemaker-induced ventricular arrhythmias has been recognized since the beginning of widespread use of artificial pacemakers, ${ }^{1-16}$ but the extent of the clinical risk of such arrhythmias has been questionable. ${ }^{17-28}$ The possibility of a dangerous arrhythmia being precipitated by a pacemaker stimulus falling during the vulnerable period of a preceding ventricular beat exists most commonly when an asynchronous artificial pacemaker is in competition with normal sinus rhythm or ectopic beats from any source. The risk is particularly great in patients requiring pacing during acute myocardial infarction, as these patients are most susceptible to life-threatening ventricular arrhythmias. ${ }^{19,20,26,27,29,30-33}$ This is a review of the reported studies of pacemaker-induced ventricular arrhythmia, with attention to the type of electrodes used, unipolar or bipolar. Every documented case of pacemaker-induced ventricular tachycardia or fibrillation occurred in association with a bipolar electrode system, adding support to the concept that these arrhythmias are evoked at the anode and do not occur with unipolar cathodal pacing.

\section{Methods}

A survey was made of all reported instances of ventricular tachycardia or fibrillation occurring in human patients with artificial ventricular pacemakers. The events were separated into two categories: (1) documented episodes in which the onset of the ventricular arrhythmia followed a pacemaker stimulus falling during the vulnerable period of the preceding beat, and (2) episodes in which the ventricular arrhythmia but not its onset was documented. There are in addition reports of pacemaker-induced ventricular arrhy thmia in which the arrhythmia was not documented, $6,12,13,20,34,35$ or in which the electrode configuration was not stated. ${ }^{34,36,37,74}$ For the purposes of this study a ventricular arrhythmia was defined as four or more responses following a pacemaker stimulus. The stimulus was judged to fall in the vulnerable period if it occurred during the $T$-wave of the preceding beat.

Each case was further categorized as bipolar or unipolar stimulation, with the assumption that in all cases of unipolar pacing the intracardiac electrode was the cathode and the indifferent electrode was the anode. Although it is possible to re-
\end{abstract}

From the Department of Medicine, Veterans Administration Hospital, University of Michigan Medical Center, Ann Arbor, Micll.

Received for publication Nov. 6, 1972.

Reprint requests to: Thomas A. Preston, M.D., Harborview Medical Center, 325 9th Ave., Seattle, Wash. 98104. 
Table I. Documented onset of pacemaker-induced ventricular tachycardia or ventricular fibrillation in humans

\begin{tabular}{|c|c|c|c|}
\hline & $\begin{array}{c}\text { Electrode } \\
\text { system }\end{array}$ & $\begin{array}{c}\text { No. of } \\
\text { patients }\end{array}$ & Arrhythmia \\
\hline Bertrand ${ }^{71}$ & Bipolar & 1 & $\mathrm{VF}^{*}$ \\
\hline Bilitch $^{33}$ & Bipolar & 1 & VF \\
\hline Castellanos 80 & Bipolar & 1 & $\mathrm{VF}$ \\
\hline Elmqvist $^{16}$ & Bipolar & 1 & $\mathrm{VF}$ \\
\hline Fletcher ${ }^{78}$ & Bipolar & 2 & $1 \mathrm{VT}, 1 \mathrm{VF}$ \\
\hline Grondin ${ }^{74}$ & Bipolar & 1 & $\mathrm{VT}$ \\
\hline Jensen $^{75}$ & Bipolar & 1 & $\mathrm{VT}$ \\
\hline Julian $^{32}$ & Bipolar & 4 & $\mathrm{VF}$ \\
\hline Kleiger $^{76}$ & Bipolar & 1 & $\mathrm{VT}$ \\
\hline Lemberg ${ }^{15}$ & Bipolar & 2 & $1 \mathrm{VT}, 1 \mathrm{VF}$ \\
\hline Preston 72 & Bipolar & 2 & $\mathrm{VF}$ \\
\hline Robinson ${ }^{4}$ & Bipolar & 1 & $\mathrm{VF}$ \\
\hline $\mathrm{Roe}^{39}$ & Bipolar & 1 & $\mathrm{VF}$ \\
\hline Tavel ${ }^{6}$ & Bipolar & 1 & $\mathrm{VF}$ \\
\hline Weinberg $7 ?$ & Bipolar & 1 & $\mathrm{VT}$ \\
\hline
\end{tabular}

*Abbreviations: $\mathrm{VT}=$ ventricular tachycardia; $\mathrm{VF}=$ ventricular fibrillation.

verse polarity in external pacing, all commercially available permanent implant pacemakers which are unipolar are fixed with anodal stimulation at the indifferent electrode.

\section{Results}

In every case of documented onset of ventricular tachycardia or ventricular fibrillation (21 cases) with the pacemaker stimulus falling in the vulnerable period of the preceding beat, the electrode system employed was bipolar (see Table I). We were unable to find such a case using a unipolar system. Sowton and Flores ${ }^{17,38}$ have reported two patients who developed ventricular fibrillation shortly after receiving permanent unipolar pacemakers which competed with normal sinus rhythms. In the first patient the onset was not documented, although the author considered it to be pacemaker-induced. He does state, however, ". . . because there is no written ECG record it is just possible that the whole sequence was due to the spontaneous onset of ventricular fibrillation." ${ }^{38}$ Sowton's second case was also undocumented, and although the patient was found with ventricular fibrillation, the episode was apparently preceded by abdominal distention, vomiting, and aspiration. In a patient reported by Roe and Katy, ${ }^{39}$ unipolar pacing did not result in a ventricular arrhythmia, whereas bipolar pacing in the same patient resulted in recurrent bouts of ventricular fibrillation. Of the 21 episodes of pacemaker-induced ventricular tachycardia, there were no reported episodes of ventricular arrhythmia arising from a pacemaker stimulus falling outside the vulnerable period.

There were 34 episodes of ventricular tachycardia or ventricular fibrillation documented in patients with functioning artificial pacemakers, but without documentation of the onset of the arrhythmia..$^{2,3,6-8,10}$, $11,14,17,18,71,73,79$ In 33 patients the pacemaker was operating as a fixed-rate (competitive) type, and one patient had a normally functioning demand (noncompetitive) unit. Twenty-eight episodes were with bipolar electrodes, and six episodes were with unipolar electrodes. Thirty episodes were ventricular fibrillation; four episodes were ventricular tachycardia.

\section{Discussion}

The problem of pacemaker-induced ventricular tachycardia or ventricular fibrillation has been studied since pacemakers have been in common use. Most reports stress the improbability of this phenomenon, but some notable exceptions have been documented. Sowton, ${ }^{3}$ in 1965 reported six patients who developed ventricular tachycardia or ventricular fibrillation while in parasystole with sinus rhythm 
and a non-inhibited fixed-rate pacemaker, and concluded that especially in the first two days after implantation there is a risk of pacemaker-induced ventricular arrhythmia. Bilitch and co-workers ${ }^{33}$ reported a case of ventricular filrillation occurring in a patient who had an acute myocardial infarction, with documentation of the onset of the arrliythmia at the time of a pacemaker stimulus falling in the vulnerable period of the preceding beat. Castellanos and coworkers ${ }^{80}$ studied 14 human patients and were able to produce "repetitive firing" in three patients and ventricular fibrillation in one patient by scanning the vulnerable period with bipolar right-ventricular pacing. Welti and colleagues ${ }^{40}$ also produced repetitive firing in humans by scanning the vulnerable period with bipolar stimuli of low amplitude. Lewis and associates, ${ }^{41}$ using unipolar pacing, were unable to produce ventricular arrhythmias.

Clinical studies comparing groups of patients with competitive and noncompetitive systems have yielded conflicting conclusions. Furman and colleagues ${ }^{25}$ report no inincreased incidence of sudden death in patients with non-triggered or competitive units, while Bilitch ${ }^{18}$ reported death due to ventricular fibrillation in 5 of 40 patients with fixed-rate units, and only one death due to ventricular fibrillation in 46 patients with demand units. Most investigators feel that pacemaker-induced ventricular arrhythmias are most likely during acute myocardial infarction, ${ }^{19,20,24,26,42}$ during the frst two days after implantation of the electrodes, ${ }^{3.23}$ or during periods of hypoxia ${ }^{24.27}$ or electrolyte imbalance. ${ }^{24,27}$ Another example of ventricular arrhythmia produced by pacing during the vulnerable period is that of paired pacing of the ventricle. Bipolar electrodes are almost always employed for paired pacing, and similarly the complication of ventricular tachycardia and fibrillation has been associated with bipolar, not unipolar, electrode systems. ${ }^{40,43-50}$

The results shown in Table I suggest an association of pacemaker-induced ventricular fibrillation with bipolar electrodes in the human. There is no documented case of human pacemaker-induced ventricular tachycardia or ventricular fibrillation with unipolar electrodes, although unipolar systems probably account for almost half of all implanted pacemakers.
Although the cardiac electrode of a permanent unipolar system is connected to the cathode of the impulse generator, in temporary systems it is possible to connect the cardiac electrode to the anode of the impulse generator, in which case the risk of anodal pacing would be the same as for a bipolar system. This could have been the situation in the two patients reported by Portal and colleagues, ${ }^{7}$ and in other cases of temporary unipolar pacing. One of two patients reported by Grondin and coworkers ${ }^{74}$ had a unipolarized electrode system with repetitive firing, but whether anode or cathode was made the indifferent electrode is not known.

Some patients with artificial pacing will develop ventricular arrhythmias not induced by a pacing stimulus. For this reason only the documented onset of pacemakerinduced ventricular tachycardia or ventricular fibrillation is acceptable as evidence of association with the electrode system in use at the time of the arrhythmia.

Numerous investigators have studied induction of ventricular arrhythmias in animals by repetitive firing during the vulnerable period. Most investigations have been carried out with bipolar electrodes ${ }^{51-54,56-59,61,66-70}$ with fewer studies of fibrillation thresholds with unipolar cathodal or anodal stimulation. ${ }^{19,55,60,62,63}$ In studies comparing anodal and cathodal stimulation, experimental evidence consistently demonstrated increased vulnerability to ventricular arrliythmias from anodal as compared to cathodal stimulation. ${ }^{42,55,60,64,65}$ Chardack and colleagues, ${ }^{19}$ using unipolar cathodal stimulation, were unable to increase the prevalence of ventricular fibrillation in dogs with acute coronary occlusion. Although this was taken as evidence of the safety of artificial pacing, it is possible that the low prevalence of fibrillation was associated with the absence of anodal stimulation.

Hoffman and Cranefield ${ }^{64}$ concluded that during induction of ventricular fibrillation with bipolar electrodes, the ventricular fibrillation is initiated at the anode. They state: "If the flow of anodal current is sufficiently diffuse, it is so difficult to evoke fibrillation that it seems safe to assume that fibrillation evoked by electrical stimulation depends upon anodal excitation." 64 
Cranefield and associates ${ }^{55}$ ruled out a double origin of ventricular fibrillation from both the anode and cathode, and concluded that the vulnerable period coincides with the period when threshold excitation occurs at the anode.

\section{Conclusions}

The association of bipolar electrodes in humans and animals with pacemakerinduced ventricular arrhythmias suggests that in the majority of instances an anode on or within the heart, of size and configuration to permit anodal stimulation, is necessary to produce ventricular tachycardia or ventricular fibrillation in humans with permanent or temporary pacing systems. As excitation during the vulnerable period is usually possible only at the anode, ${ }^{64,65}$ with the excitation threshold often ten times as great at the cathode, it does seem likely that single responses during the vulnerable period are usually evoked at the anode with presently used human pacing systems. It follows that the origin of repetitive ventricular beats, or ventricular fibrillation, is equally likely to be at the anode.

Evidence is lacking that pacemakerinduced arrhythmias are common, and commercially available pacemakers have outputs which are probably too small to produce arrhythmias in normal human hearts. It is proluable that with impulse durations of one msec. or less, as is now common with commercial units, it is almost impossible to produce arrhythmias due to pacing in the vulnerable period. ${ }^{21}$ However, commercial units must be designed to produce stimuli exceeding the excitation thresholds of 95 per cent or more of all patients encountered. With time the excitation threshold for an implanted electrode system can risc to 10 times the initial implantation threshold, and therefore pacemakers are designed to deliver 10 to 30 times as great a stimulus as is required for effective pacing at the time of electrode implantation. Therefore, under adverse conditions which lower the fibrillation threshold, such as acute myocardial infarction, hypoxia, electrolyte imbalance, or during the first two days after implantation, pacemaker-induced ventricular arrhythmias are possible, especially if the anode is on or inside the ventricle.
The use of demand (noncompetitive) pacemakers has reduced the frequency with which pacing stimuli fall in the vulnerable period of the preceding beat, but demand-type pacemakers are not totally reliable for this purpose, as they are subject to failure or outside interference in which case they perform as fixed-rate units. Especially with bipolar electrodes even a normally functioning demand pacemaker may fail to sense some spontaneous beats, resulting in competitive pacing.

The coronary care unit is a high-risk area for pacemaker-induced ventricular arrhythmias, because of the higher prevalence of ectopic beats which are not sensed by demand pacemakers and the markedly reduced fibrillation threshold of patients with acute myocardial infarction. Therefore, in the coronary care unit only unipolar cathodal pacing should be used. As most pacing in a coronary care unit is through temporary catheter electrodes, either a remote indifferent electrode (anode), or a catheter with a distal pacing electrode (callıode) and a large proximal electrode (anode at least ten times the surface area of the distal electrode) positioned outside of the right ventricle, should be used. Virtually all temporary endocardial pacing systems employ bipolar electrodes and bipolar pacemakers, such that the pacemaker anode can be attached to either electrode. Elimination of bipolar temporary systems should increase the safety of temporary pacing.

Although the danger of pacemaker-induced ventricular arrhythmia exists mostly in patients with hypoxia or acute myocardial infarction, the greater possibility of such arrhythmias with bipolar electrodes in any situation militates against the general use of bipolar electrodes.

\section{Summary}

A review of animal investigations suggests that pacemaker-induced ventricular fibrillation usually occurs at the anode, and in fact is difficult to evoke at the cathode. A search of the literature showed that every documented episode of pacemaker-induced ventricular tachycardia/fibrillation in humans has been with a bipolar electrode system. Since the problem most of ten occurs during temporary pacing associated witl myocardial infarction, bi- 
polar catheter electrodes should not he used for temporary pacing, and the use of unipolar (cathodal) pacing systems should increase the safety of electrical pacing.

\section{REFERENCES}

1. Chardack, W. S., Gage, A. A., and Greatbatch, W.: Correction of complete heart block by a self contained and subcutaneously implanted pacemaker, J. Thorac. Cardiovasc. Surg. 42:814, 1961.

2. Bonnabeau, R. C., Bilgutay, A. M., Sterns, L. P., et al.: Observations on sudden death during pacemaker stimulation in complete atrioventricular block. Trans. Am. Soc. Artif. Intern. Organs 9:158, 1963.

3. Sowton, E.: Artificial pacemaking and sinus rhythm, Br. Heart J. 27:311, 1965.

4. Robinson, D. S., Falsetti, H. L., Wheeler, D. H., et al.: Ventricular fibrillation associated with two functioning implanted cardiac pacemakers, Am. J. Cardiol. 15:397, 1965.

5. Tavel, M., and Fisch, C.: Repetitive ventricular arrhythmia resulting from artificial internal pacemaker, Circulation 30:493, 1964.

6. Bouvrain, Y., and Slama, R.: Résultats à long terme de l'entrainement électrosystolique par stimulateur intracorporel, Ann. Med. Interne (Paris) 116:397, 1965.

7. Portal, R. W., Davies, J. G., Leatham, A, et al.: Artificial pacing for the heart, Lancet 2:1369, 1962.

8. Robinson, J. S., Sloman, G., Hogan, J., et al.: Ventricular tachycardia and fibrillation with implanted electrical pacemakers, Br. Heart J. $27: 937,1965$.

9. Noordijk, J. A., Oey, F. 'T. I., and Tebra, W.: Myocardial electrodes and the danger of ventricular fibrillation, Lancet 1:975, 1961.

10. Trimble, A. S.: The implantable cardiac pacemaker: late failures and their management, J. Thorac. Cardiovasc. Surg. 50:707, 1965.

11. Laurence, G. H., Painc, R. M., and Hughes, M. I..: Management of complications associated with the use of implantable electronic cardiac pacemakers for the relief of complete heart block, Am. J. Surg. 110:177, 1965.

12. Senning, A.: Problems in the use of pacemakers, J. Cardiovasc. Surg. 5:651, 1964.

13. Spear, H. C., Daughtry, D. C., Chesney, J. G., et al.: An appraisal of the surgical management of heart block, J. Thorac. Cardiovasc. Surg. 49:743, 1965.

14. Dittmar, G. A., Friese, G., and Holder, E.: Erfahrungen uber die langfristige elektrische reizung des menschlichen herzens, 2 . Kreislaufforsch. $51: 66,1962$.

15. Lemberg, L., Castellanos, A., and Berkovits, B. V.: Pacemaking on demand in AV block, J.A.M.A. 191:12, 1965.

16. Elmqvist, R., Landegren, J., Pettersson, S. O., Senning, A., and William-Olsson, G.: Artificial pacemaker for treatment of Adams-Stokes syndrome and slow heart rate, AM. HFart J. 65:731, 1963 .
17. Sowton, E., and Flores, J.: Natural history of pacemaker patients, Bull. N. Y. Acad. Med. $47: 999,1971$.

18. Bilitch, M.: Ventricular fibrillation and pacing, Ann. N. Y. Acad. Sci. 167:934, 1969.

19. Chardack, W. M., Ishikawa, H., Fochler, F. J., et al.: Pacing and ventricular fibrillation, Ann. N. Y. Acad. Sci. 167:919, 1969.

20. Julian, D. G., Valentine, P. A., and Miller, G. G.: Disturbances of rate, rhythm and conduction in acute myocardial infarction, Am. J. Med. $37: 915,1964$.

21. Zoll, P.: Panel discussion, Ann. N. Y. Acad. Sci. 111:955, 1964 .

22. Burchell, H. B.: Analogy of electronic pacemaker and ventricular parasystole with observations on refractory period, supernormal phase and synchronization, Circulation $27: 878$, 1963.

23. Siddons, H., and Sowton, E.: Cardiac pacemakers, Springfield, 111., 1967, Charles C Thomas, Publisher, p. 109.

24. Furman, S., and Escher, D.: Principles and techniques of cardiac pacing, New York, 1970, Harper \& Row, Publishers, p. 136.

25. Furman, S., Escher, D. J., and Parker, B.: The failure of triggered pacemakers, AM. Heart J. 82:28, 1971.

26. Freidberg, C. K., Cohen, H., and Donoso, E.: Advanced heart block as a complication of acute myocardial infarction. Role of pacemaker therapy, Progr. Cardiovasc. Dis. 10:466, 1968.

27. Escher, D. J. W.: The present status of clinical cardiac pacing, AM. HEART J. 74:126, 1967.

28. Zucker, I. R., Rothfeld, E. L., Parsonnet, V., Gilbert, I.., and Bernstein, A.: Competitive idiocardiac and extrinsic pacemaker stimuli in heart block, Ax. HEART J. 69:62, 1965.

29. Dixon, M. E., 'l'rank, J. W'., and Dobell, A. R. C.: Ventricular fibrillation threshold: variation with coronary flow and its value in assessing experimental myocardial revalscularization. J. Thorac. Cardiovasc. Surg. 47:620, 1964.

30. MacLean, L. D., and Phibbs, M.: Relative effect of chronic ischemia and a myocardial revascularization procedure on the ventricular fibrillation threshold, Cirr. Res. 8:473, 1960.

31. Wolff, G. A., Veith, K., and Lown, B.: A vulnerable period for tachycardia following myocardial infarction, Cardiovasc. Res. 2:111, 1968.

32. Julian, D. G., Lassers, B. W., and Godnan, M. J.: Pacing for heart block in acute myocardial infarction, Ann. N. Y. Acad. Sci. 167:911, 1969.

33. Bilitch, M., Cosby, R. S., and Cafferky, E. A.: Ventricular fibrillation and competitive pacing, N. Engl. J. Med, 276:598, 1967.

34. Dressler, W., Jonas, S., and Rubin, R.: Observations in patients with implanted cardiac pacemakers. Repetitive responses to electrical stimuli, Am. J. Cardiol. 15:391, 1965.

35. Friedberg, H. D.: Syncope during standby cardiac pacing, Br. Heart J. 31:281, 1969

36. Palmer, I). G.: Interruption of $T$ waves by premature QRS complexes and the relationship of 
this phenomenon to ventricular fibrillation, Am. Heart J. 63:367, 1962.

37. Seldon, W. A., and Shanahan, M. X.: Ventricular fibrillation induced by artificial pacemakers, Australas. Ann. Med. 15:92, 1966.

38. Sowton, E.: Personal communication.

39. Roe, B. B., and Katy, H. J.: Complete heart block with intractable asystole and recurrent ventricular fibrillation with survival, Am. J. Cardiol. 15:401, 1965.

40. Welti, J., Fontaine, G., and Facquet, J.: Periode vulnerable: Risques possibles des rhythms interférenticls et des stimulations pairées ou couplées chez l'homme, Arch. Mal. Coeur 60:502, 1967.

41. Lewis, D. H., Warner, H. F., and Allan, M. B.: Direct measurement of human cardiac excitability (Abstract), J. Clin. Invest. 40:1058, 1961.

42. Coumel, P., Fobiato, A., Gourgon, R., et al.: Fibrillation ventriculaire et stimulateurs artificiels, Arch. Mal. Coeur 59:939, 1966.

43. Cranefield, P. F.: Paired pulse stimulation and postextrasystolic potentiation in the heart, Progr. Cardiovasc. Dis. 8:446, 1966.

44. Singer, D. H., Galst, G., and Wagner, M. L.: Effects of sustained paired stimulation of the heart in normal dogs and in dogs following coronary artery ligation, Bull. N.Y. Acad. Med. $41: 652,1965$

45. Frommer, P. L.: Studies on coupled pacing technique and some comments on paired electrical stimulation, Bull. N. Y. Acad. Med. $41: 670,1965$

46. . Cranefield, P. F.: The present status of paired pulse stimulation and postextrasystolic potentiation in the heart, Bull. N. Y. Acad. Med. $41: 736,1965$

47. Cranefield, P. F., Scherlag, B. J., Yeh, B. K., et al.: Treatment of acute cardiac failure by :maintained postextrasystolic potentiation, Bull. N. Y. Acad. Med. 40:903, 1964.

48. Chardack, W. M., Gage, A. A., and Dean, D. C.: Slowing of the heart by paired pulse pacenaking, Aın. J. Cardiol. 14:374, 1964.

49. Braunwald, N. S., Gay, W. A., Morrow, A. G., et al.: Sustained, paired electrical stimuli, Am. J. Cardiol. 14.385, 1964.

50. Han, J., Malozzi, A. M., and Lyons, C.: Ven"tricular vulnerability to paired-pulse stimulation during acute coronary ncclusion, Ам. HEART J. 73:79, 1967.

51. Wiggers, C. J.: The mechanism and nature of ventricular fibrillation, Aм. Heakt J. 20:399, 1940.

52. Miggers, C. J., and Wegria, R.: Ventricular fibrillation due to single, localized induction and condenser shock applied during the vulnerable phase of ventricular systole, An. J. Physiol. 128:500, 1940.

53. Wiggers, C. J., and Wegria, R.: Quantitative measurements of fibrillation thresholds of the mammalian ventricle with observation of the effect of procaine, Am. J. Physiol. 131:296, 1940.

54. Norman, J. C., Hays, C. V., Judge, R. D., et al, : Experimental observation on the improbability of totally implantable pacemaker-induced ventricular fibrillation, Trans. Am. Soc. Artif. Intern. Organs 10:378, 1964.

55. Cranefield, P. F., Hoffman, B. F., and Siebens, A. A.: Anodal excitation of cardiac muscle, Am. J. Physiol. 190:383, 1957.

56. Widmann, W. D., Eisenberg, L., Levitsky, S., et al.: Ventricular fibrillation complicating electrical pacemaking: Comparison of direct current and radio frequency cardiac pacemaker stimulation, Surg. Forum 14:260, 1963.

57. Hoffman, B. F., Gorin, E. F., Wax, F. S., et al.: Vulnerability to fibrillation and the ventricularexcitability curve, Am. J. Physiol. 167:88, 1951.

58. Chardack, W. M.: Heart block treated with an implantable nacemaker, Progr. Cardiovasc. Dis. 6:507, 1964

59. Hoffman, B. F., Suckling, E. E., and Brooks, C. McC.: Vulnerability of the dog ventricle and effects of defibrillation, Circ. Res. 3:147, 1955.

60. Harris, A. S., and Moe, G. K.: Idioventricular rhythms and fibrillation induced at the anode or the cathode by direct currents of long duration, Am. J. Physiol. 136:318, 1942.

61. Moe, G. K., Harris, A. S., and Wiggers, C. J.: Analysis of the initiation of fibrillation by electrographic studies, Am. J. Physiol. 134:473, 1941.

62. Brooks, C. McC., Cranefield, P. F., Hoffman, B. F., et al.: Anodal effects during the refractory period of cardiac muscle, J. Cell Physiol $48: 237,1956$.

63. Van Dam, R. T., Durrer, D., Strackee, J., et al.: Excitability cycle of the dog's left ventricle determined by anodal, cathodal and bipolar stimulation, Circ. Res. 4:196, 1956.

64. Hoffman, B. F, and Cranefield, P. F.: Electrophysiology of the heart, New York, 1960, McGraw-Hill Book Company, Inc., p. 225.

65. Surawicz, B.: Ventricular fibrillation, Am. J. Cardiol. 28:268, 1971

66. Parker, B. M., Shine L. C., Burford T., et al.: Indwelling electronic cardiac pacemakers, J.A.M.A. 186:754, 1963.

67. Rothfeld, E. L., Zucker, I. R., Parsonnet, V., et al.: Effect of quinidine on competitive cardiac pacing ( $\Lambda$ bstract), Circulation 32(Suppl. 2):182, 1965.

68. Wiggers, C. J., Wegria, R., and Pinera, B.: The efferts of myocardial ischemia on the fibrillation threshold-the mechanism of spontaneous ventricular fibrillation following coronary occlusion, Am. J. Physiol. 131:309, 1940.

69. Groundin, P., LePage, G., Guignard, J., et al.: Evaluation of cardiac drugs in the presence of an electrical pacemaker, J. Thorac. Cardiovasc. Surg. 48:941, 1964.

70. Gerst, P. F., Fleming, W. H., and Malon, J. R.: Increased susceptibility of the heart to ventricular fibrillation during metabolic acidosis, Circ. Res. 19:63, 1966

71. Bertrand, M., Cabrol, C., Guiraudon, G., et al.: Fibrillation ventriculaire aprés implantation de stimulateur interne Presse Med. 75:1455, 1967.

72. Preston, T. A.: Unpublished data. 
73. Tancredi, R. G., McCallister, B. I)., and Mankin, H. T.: Temporary transvenous catheter-electrode pacing of the heart, Circulation 36:598, 1967.

74. Grondin, P., LePage, G., Karamehmet, A., et al.: Pacemaker-induced repetitive firing. Report of two cases, Can. Med. Assoc. J. 96:1477, 1967

75. Jensen, N. K., Schmidt, R., Garamella, J. J., el al.: Intlacavitary cardiac pacing, J.A.M.A. 195:916, 1966 .
76. Kleiger, R.: Personal communication.

77. Weinberg, S.: Personal communication.

78. Fletcher, R.: Personal communication.

79. Paulk, E. A., and Hurst, J. W.: Complete heart block in acute myocardial infarction, Am. J. Cardiol. 17:695, 1966.

80. Castellanos, A., Lemberg, L., and Berkovits, B. V.: Repetitive firing during synchronized ventricular stimulation (Abstract), Am, J. Cardiol. 17:119, 1966. 